\title{
Avaliação da conduta ética da comunidade de Seropédica-RJ na compra de produtos
}

\section{sem vendedor}

\author{
Evaluation of the ethical conduct of the Seropédica-RJ community when buying products without a
}

seller

\section{Evaluación de la conducta ética de la comunidad Seropédica-RJ al comprar productos sin vendedor}

\section{Resumo}

A disseminação da ideia de que atos de corrupção são cotidianos e aceitáveis no Brasil trouxe uma imagem negativa da nossa sociedade. Nos últimos anos, a nível profissional, começou-se a cobrar, além dos conhecimentos técnicos, os valores éticos e morais na conduta profissional. Assim, iniciar projetos de ética é importante para trazer a discussão um tema atual, pouco disseminado e muito controverso aos alunos do ensino superior. O presente trabalho é resultado de dois anos de pesquisa desenvolvido pelo grupo PET-Floresta, nos anos de 2017 e 2018 . A ideia central do projeto foi testar a honestidade da comunidade acadêmica e do entorno da Universidade Federal Rural do Rio de Janeiro por meio da venda de produtos sem a presença de um vendedor formal no local. Verificamos que o projeto despertou a atenção de 670 pessoas e obteve apenas $1 \%$ de delitos. Tal resultado provou que a corrupção não é algo comum entre as atitudes na comunidade estudada.

Palavras-chave: Responsabilidade social; Corrupção; Universidade; Práticas sociais.

\begin{abstract}
The spread of the idea that acts of corruption are daily and acceptable in Brazil, brought a negative image of our society. In recent years, on a professional level, the ethical and moral values of professional conduct have been collected in addition to technical knowledge. Thus, initiating ethics projects is important to bring the discussion a current topic, little disseminated and very controversial to students of higher education. The present work is the result of two years of research developed by the PET-Floresta group in the years 2017 and 2018. The main idea of the project was to test the honesty of the academic community and surroundings of UFFRJ through the sale of products without the presence of a formal seller on the spot. We verified that the project attracted the attention of 670 people and obtained only $1 \%$ of crimes. This result proved that corruption is not something common among the attitudes of the community studied.
\end{abstract}

Keywords: Social responsibility; Corruption; University; Social practices.

\section{Resumen}

La difusión de la idea de que los actos de corrupción son cotidianos y aceptables en Brasil trajo una imagen negativa de nuestra sociedad. En los últimos años, a nivel profesional, comenzó a exigir, además de conocimientos técnicos, valores éticos y morales en la conducta profesional. Así, poner en marcha proyectos de ética es importante para llevar a la 
discusión un tema de actualidad, poco difundido y muy controvertido entre los estudiantes de educación superior. Este trabajo es el resultado de dos años de investigación desarrollados por el grupo PET-Forest, en 2017 y 2018 . La idea principal del proyecto era probar la honestidad de la comunidad académica y el entorno de la Universidad Federal Rural de Río de Janeiro mediante la venta de productos sin la presencia de un vendedor formal en el lugar. Descubrimos que el proyecto atrajo la atención de 670 personas y solo obtuvo un 1\% de infractores. Este resultado demostró que la corrupción no es común entre las actitudes de la comunidad estudiada.

Palabras clave: Responsabilidad social; Corrupción; Universidad; Prácticas sociales.

\section{Introdução}

A noção de ética gira em torno de princípios e valores orientados na ação do estabelecimento de regras para o bem de uma sociedade (Caetano \& Silva, 2009). A ética normalmente está associada a valores como: respeito, solidariedade, justiça, imparcialidade, igualdade, honestidade, verdade e responsabilidade. A chamada ética universal é pertencente a natureza humana, sendo indispensável para a convivência entre pessoas (Freire, 1996; Jucá \& Mattos, 2021). De forma prática, pode se dizer que os desvios éticos estão relacionados à escolha dos objetivos do indivíduo (Serodio, Kopelman, \& Bataglia, 2016), ou seja, ao não cumprimento dos valores definidos para o bem de uma sociedade. A falta e a quebra da ética podem desestimular comunidades, setores e, até mesmo, a cultura de um país.

Ações e decisões éticas são de extrema importância na vida pessoal e profissional de um cidadão. Na atualidade, a má conduta ética é motivo de diversas manchetes atraentes para jornalistas (Erzikova, 2010). Na esfera política a falta de ética pode ser evidenciada por meio de ações corruptas. Na última década, notícias e denúncias de corrupção no meio político e empresarial foram recorrentes no Brasil. Casos de má administração e uso indevido de recursos públicos, redes de estruturas organizadas sob propina e tantos outros escândalos que configuram uma sensação de mal-estar coletivo, em que sempre olhamos de modo muito cético os rumos que a política segue no Brasil (Filgueiras, 2009). Tais fatos não mudaram nos últimos anos e continua-se a gerar dúvida a integridade e condução de diversos setores públicos e privados brasileiros.

Essa sensação de mal-estar coletivo com a corrupção cria concepções de senso comum acerca de um natural desonestidade do brasileiro (Faoro, 2001; Filgueiras, 2009). O mesmo autor relata que um dos traços característicos de senso comum é que o brasileiro típico tem um caráter duvidoso e que, a princípio, não se nega a levar algum tipo de vantagem dentro de suas relações sociais. Com isso, vários indicadores de confiança apontam o Brasil como um país onde a desconfiança impera.

Pesquisas realizadas pela Transparência Internacional, a respeito da percepção da corrupção em inúmeros países, têm colocado o Brasil, ao longo dos anos, em posições nada elogiáveis. Em vinte anos, a classificação do Brasil oscilou - em uma escala de zero a cem - de uma nota de 41 em 1999, para 39 em 2003; 37 em 2008; 43 em 2014; 38 em 2015; 40 em 2016; 37 em 2017; chegando a 35 em 2018 e permanecendo até 2019, atingindo a pior colocação já registrada para o país na série histórica do índice. Para efeito de comparações, os dois países mais bem avaliados em 2019 (Dinamarca e Nova Zelândia) receberam a nota 87(Transparência Internacional, 2019). Os dados são apenas registros parciais e dispersos que demonstram que a corrupção no Brasil tem assumido diversas formas e proporções extremamente preocupantes. Em seu estágio atual, a corrupção impõe danos às estruturas sociais e econômicas, e coloca em discussão a atuação das organizações produtivas nos diversos setores da economia nacional.

Nos últimos anos o mercado se tornou cada vez mais dependente das relações entre pessoas e o meio em que atua, na qual as empresas se veem na obrigação de satisfazer os múltiplos interesses da sociedade (Alves De Jesus, Sarmento, \& Duarte, 2017). Assim, para responder com sucesso as diversas expectativas das chamadas "partes interessadas" torna-se necessário questionar constantemente seus quesitos legais e éticos, no mesmo patamar de seus interesses econômicos. Isso tem direcionado as empresas a serem consideradas como um centro de responsabilidade social, interna e externamente, levantando-se, assim, uma importante dimensão ética (Alves De Jesus et al., 2017; Cortella, 2015).

Entende-se que que os valores éticos são difíceis de ser impostos e que, nas organizações, correspondem ao somatório 
da ética de todos os seus colaboradores. Assim, pode se dizer que a ética se encontra nas pessoas que compõem a empresa e que quando praticada e aplicada pelos seus trabalhadores, constitui uma forma de corrigir as decisões e condutas inadequadas da empresa (Carvalho, 2011). Deste modo, o comportamento ético e socialmente responsável dos trabalhadores é muito importante para as organizações responderem e mudarem, de forma viável, as necessidades e expectativas das partes interessadas (Alves De Jesus et al., 2017).

Entretanto, a disseminação da ideia de que atos de corrupção são cotidianos e aceitáveis no Brasil, trouxe uma imagem negativa a nossa sociedade em âmbito geral. Em nível profissional, começou-se a cobrar, além dos conhecimentos técnicos, os valores éticos e morais em sua conduta profissional. De acordo com o entendimento de (Filgueiras, 2009) o controle da corrupção não depende apenas do desenho das instituições do Estado, mas também de uma vontade cidadã que controle e impeça a escalada da corrupção.

Nesse sentido, iniciar projetos de ética torna-se importante para trazer a discussão de um tema atual, pouco disseminado e muito controverso aos alunos do ensino superior. Razera e Nardi (2006) em um trabalho sobre ética no ensino de ciências concluíram que todas as escolas deveriam incentivar o aprimoramento dos seus professores para uma melhor atuação em discussões de ética e moral no ensino, visto que são responsáveis pelo desenvolvimento moral de seus alunos ao se tornarem exemplos. Assim como as universidades, responsáveis pelo tripé indissociável do ensino, pesquisa e extensão, na qual inclui-se também a formação de todos os professores (Razera \& Nardi, 2006).

Frente a essa problemática, o grupo PET-Floresta iniciou um projeto com o intuito de testar a honestidade da comunidade acadêmica e adjacências do campus Seropédica da Universidade Federal Rural do Rio de Janeiro (UFRRJ) e a partir destes resultados refletir sobre os valores éticos presentes na sociedade. Por fim, ao discutir a presente temática espera-se agregar valor aos futuros profissionais da engenharia florestal da UFRRJ e promover a conscientização da sociedade como um todo.

\section{Metodologia}

O presente estudo foi desenvolvido pelo grupo PET-Floresta: Formação Através de Vivências em Atividades Florestais Sustentáveis, formado por alunos e um professor do curso de engenharia florestal da Universidade Federal Rural do Rio de Janeiro, pertencente ao Programa de Educação Tutorial do MEC. O programa tem como principal objetivo trabalhar a tríade do ensino superior - ensino, pesquisa e extensão nas universidades brasileiras. De forma a internalizar a tríade e trabalhar o conceito de ética/honestidade no entorno da Universidade o grupo desenvolveu uma pesquisa pautada na ética de pagamento por produtos ofertados sem a presença física de um vendedor. Todos os produtos comercializados no projeto foram doados pelo Supermercado Seropédica. Ressalta-se aqui que encontramos outros trabalhos reproduzindo atividades similares, mas nenhum em publicação científica.

A pesquisa realizada foi de caráter qualitativo (Ludke \& Andre, 2013), a fim e entender o comportamento social da população residente no município de Seropédica e dos alunos da Universidade Federal Rural do Rio de Janeiro (UFRRJ). Para obtenção do dados foi realizada a montagem de uma mesa com pequenos produtos alimentícios (doces e balas) à venda por um valor unitário e simbólico de $\mathrm{R} \$ 1,00$. Essa mesa foi disposta em locais diversos do campus Seropédica da UFRRJ e entorno, com grande circulação de pessoas. O projeto foi divido em duas etapas, a primeira foi constituída pela pesquisa dentro da universidade, estratificada em dois blocos de observação:

- O primeiro foi caracterizado pela amostragem nos seguintes locais: saída do Restaurante Universitário, hall do Pavilhão Central e sala de estudos dos estudantes.

- O segundo bloco foi composto por amostragem nos seguintes locais: saída do Restaurante Universitário, sala de estudos dos estudantes e entrada do Pavilhão de Aulas Teóricas.

A pesquisa nas dependências da universidade se deu nos meses de maio e junho de 2017, totalizando sete dias de 
amostragens, com realização nos horários de maior movimentação de acordo com as atividades dos locais. Em decorrência da viabilidade de realização, a segunda etapa da pesquisa foi realizada no centro do município de Seropédica, em junho de 2018 . A mesa foi disposta na Praça Nildo Romano, km 49, próximo ao local de maior trânsito de pessoas, e contou com três dias de observações. A disposição da mesa era composta apenas pelos doces, uma caixa trancada para depósito do valor do produto a ser comprado e cartazes informativos com as instruções de compra (Figura 1).

Figura 1 - Mesa com os doces à venda e a caixa para o deposito do dinheiro.

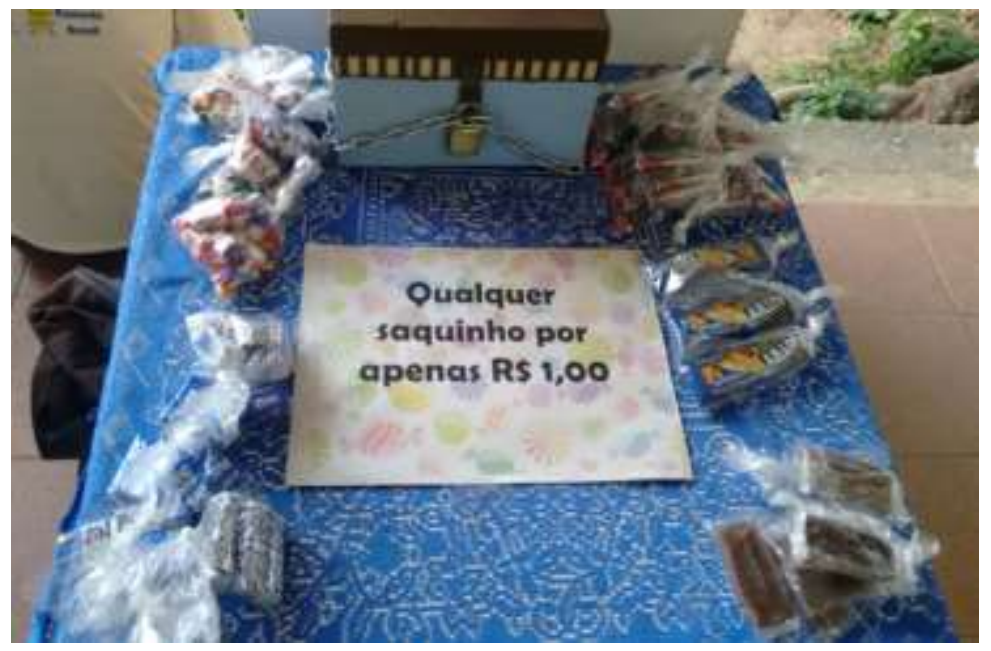

Fonte: Autores (2021).

Os locais foram escolhidos em decorrência do grande fluxo de alunos de diferentes cursos, moradores e comerciantes, com idades e poder aquisitivo distintos, configurando-se assim em uma amostra heterogênea. Além disso, no Prédio Principal estão localizadas as principais secretarias da Universidade, uma agência dos correios e a única agência do Banco do Brasil do município de Seropédica. O dia escolhido para a coleta de dados também contemplou a presença da feira orgânica semanal de produtores municipais. Desta forma, pode-se atingir também professores e técnicos da universidade e parte da população da cidade que utiliza os serviços disponíveis neste espaço.

Ao final de cada etapa os valores monetários oriundos do pagamento pelos produtos foram contabilizados e os itens não vendidos quantificados. Para obtenção do percentual de delitos ou atos de corrupção foi utilizada a diferença entre os valores encontrados e a quantidade de doces restantes. Para uma análise descritiva das reações das pessoas os integrantes do grupo PETFloresta responsáveis pela atividade permaneceram próximo aos locais de disposição da mesa, de forma a não serem associados com a mesa, e observaram as reações sociais dos envolvidos. Para tal, foi elaborada uma ficha avaliativa onde constavam as seguintes situações: observou a mesa; observou e leu o cartaz; olhou ao redor; não olhou ao redor; pegou o doce sem pagar; pagou pelo doce; observações adicionais. O intuito da análise descritiva foi verificar se haveria influência de outras pessoas nos casos de retirada sem pagamento dos produtos ou constatar se seria verificado casos em que as pessoas iriam questionar a atitude dos demais pelo não pagamento do produto.

\section{Resultados e Discussão}

A primeira etapa do projeto contou com um total de sete amostragens, variando entre horários e locais de exposição da mesa, todas dentro do campus da UFRRJ. Os valores esperados e arrecadados das duas etapas podem ser observados na Tabela 1. 
Tabela 1 - Quantidades iniciais e finais dos doces à venda com valores referentes.

\begin{tabular}{|c|c|c|c|}
\hline & \multicolumn{2}{|c|}{ Etapa 1} & \multirow{2}{*}{ Etapa 2} \\
\hline & Bloco 1 & Bloco 2 & \\
\hline Quantidade inicial & 140 & 92 & 85 \\
\hline Quantidade final & 61 & 0 & 78 \\
\hline Valor arrecadado $(\mathbf{R} \$)$ & 81,55 & 86,05 & 7 \\
\hline Valor esperado (R\$) & 79 & 92 & 7 \\
\hline
\end{tabular}

Fonte: Autores (2021).

O bloco 1 apresentou resultados muito positivos no que tange a ética e empatia pelo trabalho de outrem, uma vez que foi encontrado valor superior ao valor esperado com a venda dos doces. Dentre os locais amostrados somente havia presença da vigilância universitária no Pavilhão Central. Local esse que deteve o maior tempo de exposição das mercadorias em virtude da grande movimentação de alunos, funcionários e moradores da região.

No entanto, no bloco 2 o saldo foi inferior ao esperado, mostrando que houve maior retirada de produtos do que pagamento pelos mesmos (Tabela 1). Nessa fase foram mantidas as exposições no Restaurante Universitário (RU), Pavilhão de Aulas Teóricas (PAT) e Sala de estudos. O PAT é um dos locais mais movimentados do campus da UFRRJ, uma vez que comporta aulas de diferentes cursos e possui grande circulação de alunos, professores e funcionários durante todos os períodos do dia, entretanto não há presença de vigilância no local. Foi observado que o PAT teve a maior taxa de vendas assim como a maior taxa de delitos dentre os locais amostrados nessa fase, representando aproximadamente 5,4\% dos pagamentos esquecidos. O RU também contou com um percentual de delitos com 1,1\% aproximadamente.

É importante destacar que os locais e horários escolhidos foram decorrentes da maior movimentação de pessoas, ressaltando-se que os maiores períodos de venda dos doces ocorreram no hall do Pavilhão Central e PAT, ficando em exposição por 09 e 07 horas, respectivamente. Isso traz uma importante reflexão acerca do comportamento das pessoas na comunidade estudada. Não foi verificado nenhum delito no Pavilhão Central, possuindo este guardas patrimoniais e funcionários fixos em sua porta de entrada, próximo de onde ficou alocada a mesa com os produtos vendidos. Já no PAT foi verificado o maior índice de esquecimento do pagamento pelos produtos levados, não possuindo nenhuma vigilância imediata. Pondera-se a partir disso que os atos desonestos da comunidade podem ter sido inibidos pela presença de algum tipo de vigilância. A segunda etapa do projeto foi realizada fora das dependências da UFRRJ, na Praça de Seropédica, por três dias distintos. Nessa fase a mesa foi colocada próxima à passagem dos pedestres que circulam pela praça. Entretanto, foi observado que pouquíssimas pessoas se atentavam para a mesa, muitos até desviavam sem olhar o conteúdo exposto. Nenhum delito foi identificado e apenas sete doces foram vendidos em todo o tempo em que a mesa ficou exposta (Tabela 1).

Os resultados encontrados com esse projeto indicam valores muito satisfatórios, pois do total de 178 doces retirados foi contabilizado a ausência do valor correspondente a apenas seis doces. Isso mostra que a corrupção ou a falta de ética neste quesito ainda não assola fortemente a comunidade amostrada, mesmo que os casos de não pagamento tenham ocorrido nela. É importante lembrar que foi detectada também quantia superior ao esperado na primeira amostragem, indicando que ainda há sensibilização dos que participaram da iniciativa comprando e deixando uma cortesia como empatia a situação exposta. Nesse sentido, pode-se relacionar a educação com a ética, uma vez que propicia a geração de recursos humanos voltados para a construção de valores humanos (Arroyo, 2007; Salvador, 2007)

Esses dados corroboram com os encontrados pelo professor André Luis Shiguemoto em pesquisa similar na Universidade Tecnológica Federal do Paraná (UTFPR). No estudo foram dispostos picolés para a venda sem a presença física de vendedor, assim como no presente estudo, a fim de educar a comunidade acadêmica envolvida e despertar o sentimento de 
confiança e filantropia. Para ele "a honestidade não tem relação somente com o nível de instrução, mas também com os exemplos que temos dentro de casa, são valores que cultivamos" (Folha de Londrina, 2016). No estudo foram vendidos 2.399 sorvetes com ausência de pagamento de apenas 50, apresentando assim uma média de não pagantes de apenas 2,4\%. Além disso, também foi relatado na pesquisa que após um crescimento de inadimplência (ausência de pagamentos) os idealizadores do projeto realizaram uma campanha de conscientização entre os discentes. Após a campanha os pesquisadores verificaram que o valor total dos pagamentos foi superior ao real valor cobrado pelos produtos. O professor André relatou que após as campanhas o projeto passou a ter um caráter mais solidário.

Assim como no presente estudo, a taxa de inadimplência foi considerada baixa e, para o idealizador do projeto "Confiança e Solidariedade em Palitos" o ambiente universitário contribui para os índices considerados baixos e acredita que experimentos como esses em outros ambientes poderiam apresentar resultados distintos. Porém, assim como foi observado na comunidade exterior à universidade por este estudo, em uma iniciativa realizada pela entidade Casa do Caminho em Poços de Calda (MG), mostrou resultados muito positivos frente à sociedade. Nessa iniciativa biscoitos foram colocados à venda em corredores de shopping, hospitais e restaurantes e os resultados surpreendem no que tange a honestidade e solidariedade das pessoas, onde, mais uma vez foi encontrado valor superior pela venda dos produtos (G1 Sul de Minas, 2014).

Uma análise mais profunda leva a considerações importantes sobre o perfil dos envolvidos, pois nota-se que a comunidade acadêmica tem maior percepção do que está a sua volta. Verificou-se que os alunos e professores se atentaram mais para o que é anunciado no seu entorno e tiveram maior empatia pelos dizeres do cartaz, que apresentavam informações sobre a necessidade de venda dos produtos e impossibilidade de tempo para vendê-los. Cabe ressaltar que a venda de produtos alimentícios por estudantes é uma atividade recorrente na universidade, o que pode contribuir para a maior atenção ao anúncio deste projeto. Todavia, fora do ambiente universitário foi observado falta de percepção das pessoas que circulam pelo centro comercial de Seropédica. Verificou-se que poucas pessoas observaram ou mesmo pararam para ler o cartaz. Ficou evidente que a mesa era apenas mais um obstáculo na correria diária e não despertou muita atenção dos transeuntes.

A descrição do comportamento dos envolvidos a partir das observações realizadas pelos estudantes responsáveis pelo projeto indicou que muitas pessoas leram os cartazes informativos, mas destes apenas uma pequena parcela se interessou pelos produtos (Tabela 2).

Tabela 2 - Resultados das observações in loco das reações dos envolvidos no projeto.

\begin{tabular}{lccccc}
\hline \multirow{2}{*}{ Observações } & \multicolumn{5}{c}{ Locais de amostragem } \\
\cline { 2 - 6 } & RU & SE & P1 & PAT & Praça \\
\hline Somente observou a mesa & 33 & 46 & 46 & 60 & 41 \\
Observou a mesa e leu o cartaz & 60 & 33 & 46 & 100 & 18 \\
Olhou ao redor & 8 & 6 & 2 & 3 & 6 \\
Não olhou ao redor & 32 & 4 & 3 & 0 & 3 \\
Pegou o doce sem pagar & 4 & 0 & 0 & 0 & 0 \\
Pagou pelo doce & 18 & 7 & 28 & 56 & 5 \\
\hline
\end{tabular}

Onde: $\mathrm{RU}=$ Restaurante Universitário SE = Sala de estudos; $\mathrm{P} 1$ = Pavilhão central; $\mathrm{PAT}=$ Pavilhão de Aulas Teóricas; Praça = Praça Nildo Romano (Centro de Seropédica). Fonte: Autores (2021).

Foi observado que aproximadamente 670 pessoas passaram pelo projeto considerando todos os locais amostrados. As estimativas percentuais podem ser observadas na Figura $2 \mathrm{e}$, segundo os dados referentes à observação da conduta dos envolvidos, o percentual de delitos foi de apenas $1 \%$ dos participantes. É muito importante destacar que conclusões baseadas apenas na observação do comportamento humano não podem ser decisórias, uma vez que pode ser identificado que algumas 
observações não condizem com a apuração da urna de dinheiro arrecado. Como no caso observado no PAT, não houve nenhuma observação aparente de delitos cometidos, entretanto foi apurado que um valor monetário menor que o esperado. E, no RU, foi observado um número superior de delitos em comparação ao valor monetário quantificado.

Figura 2 - Valores percentuais de participação da comunidade acadêmica e sociedade no projeto.

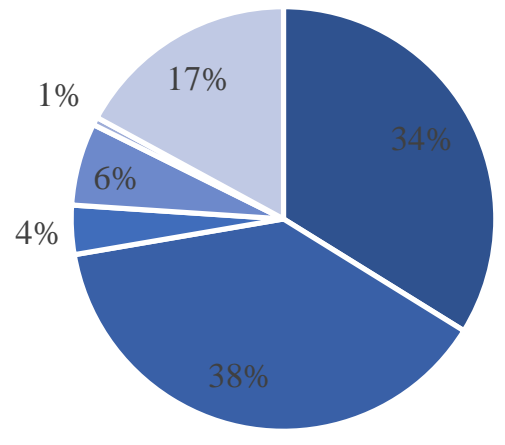

\author{
- Somente observou a mesa \\ - Observou a mesa e leu o cartaz \\ - Olhou ao redor \\ - Não olhou ao redor \\ - Pegou o doce sem pagar \\ Pagou pelo doce
}

Fonte: Autores (2021).

Com a presente análise pode-se perceber que os resultados foram satisfatórios em todos os locais. A honestidade, solidariedade e empatia podem ser observadas na comunidade acadêmica e no centro do município de Seropédica. Por fim, entende-se que os resultados obtidos podem auxiliar a discussão sobre a corrupção e desonestidade que assola os mais variados setores do nosso país (Marcovitch, 2017) e desenvolver atitudes que sirvam de exemplo e consigam cada vez mais despertar os caminhos de uma conduta ética, justa e solidária na sociedade brasileira (Nunes-Neto \& Conrado, 2021). Os resultados indicaram que esse projeto tem fundamento, pois a quantidade de doces levados sem pagar foi relativamente baixa. Dessa forma, apesar da baixa amostragem, pode-se inferir que a maior parte da sociedade amostrada é honesta, tendo, portanto, princípios éticos presentes, contrariando a afirmação de que atos de corrupção são cotidianos. Nessa perspectiva, a sociedade de Seropédica e os alunos da UFRRJ podem servir de modelo para aplicação do estudo em outras instituições, a fim de permitir trabalhos sociais que desenvolvam questões sociais e éticas (Igiri, Achigbe, \& Effiong, 2019)

Esse era o resultado esperado, principalmente em uma época onde a corrupção é o foco das principais notícias nacionais, torna-se muito importante mostrar que a maioria da sociedade brasileira não compactua com tais atos ilícitos. Entretanto, o percentual de doces furtados mostra que é necessária a realização de projetos que trabalhem os conceitos de ética dentro e fora da universidade, como um difusor de boas condutas.

\title{
4. Considerações Finais
}

O projeto despertou a atenção de 670 pessoas e obteve apenas $1 \%$ de delitos entre as observações. Além disso, consideramos os resultados positivos no que tange a ética e empatia pelo trabalho de outrem, uma vez que foi encontrado valor superior ao valor esperado com a venda dos doces em algumas amostragens. O resultado ao todo foi satisfatório, pois a porcentagem de delitos foi considerada baixa, o que pode indicar que desonestidade ainda não assola a comunidade em que foi feito o estudo. Entendemos que tais resultados podem contribuir para desfazer a ideia de que a corrupção é uma conduta comum ao cotidiano brasileiro, e que sim a ética se faz presente na maioria da população estudada. 
Research, Society and Development, v. 10, n. 8, e28010817360, 2021

(CC BY 4.0) | ISSN 2525-3409 | DOI: http://dx.doi.org/10.33448/rsd-v10i8.17360

\section{Referências}

Alves De Jesus, T., Sarmento, M., \& Duarte, M. (2017). Ética e responsabilidade social. Dos Algarves: A Multidisciplinary e-Journal, 29 , 3-30.

Arroyo, M. G. (2007). Sistema de Información Científica. Pesquisa Revista e-Curriculum, 2(2). http://www.redalyc.org/articulo.oa?id=76620202

Caetano, A. P., \& Silva, M. de L. (2009). Ética profissional e Formação de Professores. Sísio, Revista de Ciências da Educação, 49-60.

Carvalho, J. A. (2011). Ética e Liderança - A Crise no Sector Imobiliário. (Vida Imobiliária, Ed.).

Cortella, M. S. (2015). Educação, convivência e ética - audácia e esperança! (Cortez, Ed.).

Erzikova, E. (2010). University teachers' perceptions and evaluations of ethics instruction in the public relations curriculum. Public Relations Review, 36(3), 316-318. JAI.

Faoro, R. (2001). Os Donos do Poder.://groups.google.com.br/group/digitalsource

Filgueiras, F. (2009). A tolerância à corrupção no Brasil: uma antinomia entre normas morais e prática social. Opinião Pública, 15(2).

Folha de Londrina. (2016). Confiança e solidariedade em palitos. https://www.folhadelondrina.com.br/norte-pioneiro/confianca-e-solidariedade-em-palitos942351.html

Freire, P. (1996). Pedagogia da autonomia: saberes necessários à prática educativa. (Paz e Terra, Ed.) (65th ed.).

G1 Sul de Minas. (2014). G1 - Projeto desperta honestidade com venda de biscoitos em Poços, MG - notícias em Sul de Minas. http://g1.globo.com/mg/sul-deminas/noticia/2014/08/projeto-desperta-honestidade-com-venda-de-biscoitos-em-pocos-mg.html

Igiri, C. E., Achigbe, J. O., \& Effiong, O. E. (2019). Teaching Science Education with special reference to Morals, Values, Ethics, And Character Education. IJRDO - Journal of Educational Research, 4(7), 1-13. http://www.ijrdo.org/index.php/er/article/view/2992/2425

Jucá, L. C. V., \& Mattos, A. M. de A. (2021). Education in Brazil: A Discussion of Current Problems and a Call to Action. Revista Brasileira de Linguística Aplicada, 21(2).

Ludke, M., \& Andre, M. E. D. A. (2013). Pesquisa em educação: abordagens qualitativas. (E.P.U, Ed.) (2nd ed.).

Marcovitch, J. (2017). Como salvar a política? Estudos Avançados, 32(92).

Nunes-Neto, N., \& Conrado, D. M. (2021). Ensinando Ética. Educação em Revista, 37.

Razera, J. C. C., \& Nardi, R. (2006). Ética no ensino de ciências: Responsabilidades e compromissos com a evolução moral da criança nas discussões de assuntos controvertidos. Investigações Em Ensino de Ciências, 11, 53-66.

Salvador, R. (2007). Roberto Salvador. Franca, SP.

Serodio, A., Kopelman, B. I., \& Bataglia, P. U. R. (2016). Promoting moral and democratic competencies: towards an educational turn of Bioethics. Revista Bioética, 24(2).

Transparência Internacional. (2019). Transparência Internacional - Brasil. https://transparenciainternacional.org.br/home/corrupcao-e-saude 